\title{
PENERAPAN ERGONOMI PADA PEKERJA PT. MAKASSAR BETON PERKASA DI KOTA MAKASSAR
}

Ergonomic Application In Workers Pt. Makassar Beton Perkasa In City Of Makassar Muh. Ikbal Arif ${ }^{1}$ dan Harold Geraldy Firstyliano ${ }^{2}$

1,2 Jurusan Kesehatan Lingkungan Poltekkes Kemenkes Makassar mikbalarif@gmail.com

\begin{abstract}
Ergonomics is one of the indispensable factors in company. Ergonomics provides confidence that the suitability of the product. With human users of the product, will improve the work. Then For the improvement of these results there needs to be efforts. Ergonomics within the company so that what is expected to be achieved. This study aims to determine work attitude, complaints. Work, temperature and humidity in the office, and the use of tools. Personal protector in the factory PT. Makassar Beton Perkasa. The type of research used is the observational method of data. Collected from survey results, observations, and questionnaires used. To get results or information about ergonomics work attitude On workers. With technique using total sampling counted 40 . Workers in the office and factory in PT. Makassar Beton Perkasa. The results showed that PT. Makassar Beton Perkasa Only on the part of the office only in accordance with the work attitude of ergonomics, As well as qualify the room temperature and humidity. While on The parts of the factory are very inconsistent with ergonomic work attitude even Personal protective equipment (PPE) for workers is not available, because it is not Industrial efforts to facilitate it. Based on the results of the study, due to the large number of labor. Which has a work complaint, then suggested industry PT. Makassar The Mighty Concrete should build a rest area for the workers factory.
\end{abstract}

Keywords: Safety and health, Ergonomics, Availabily of PPE

\section{ABSTRAK}

Ergonomi merupakan salah satu faktor yang sangat dibutuhkan dalam perusahaan. Ergonomi memberikan keyakinan bahwa kesesuaian produk dengan manusia pengguna produk, akan meningkatkan hasil kerja. Maka untuk peningkatan hasil tersebut perlu adanya upaya-upaya yang ergonomi dalam perusahaan sehingga apa yang diharapkan tercapai.Penelitian ini bertujuan untuk mengetahui sikap kerja, keluhan kerja, suhu dan kelembaban di bagian kantor, dan penggunaan alat pelindung diri di bagian pabrik PT. Makassar Beton Perkasa. Jenis penelitian yang digunakan adalah metode observasional yaitu data terkumpul dari hasil survey, observasi, dan kuesioner yang digunakan untuk mendapatkan hasil atau informasi tentang sikap kerja ergonomi pada pekerja. Dengan teknik menggunakan total sampling sebanyak 40 pekerja di bagian kantor dan pabrikdi PT. Makassar Beton Perkasa.Hasil penelitian menunjukkan bahwa industri PT. Makassar Beton Perkasa hanya pada bagian kantor saja yang sesuai dengan sikap kerja ergonomi, serta memenuhi syarat suhu dan kelembaban ruangan. sedangkan pada bagian pabrik sangat tidak sesuai dengan sikap kerja ergonomi dan alat Pelindung diri (APD) bagi pekerja terbatas, karena tidak adanya upaya Industri untuk memfasilitasi bagi semua pekerja.Berdasarkan hasil penelitian tersebut, disimpulkan bahwa tenaga kerja di PT, Makassar beton Perkasa masih banyak yang bekerja tidak ergonomis, sehingga menimbulkan keluhan terhadap pekerja dan masih kurangnya APD yang disediakan bagi pekerja, maka disarankan industri PT. Makassar Beton Perkasa sebaiknya memperhatikan kenyamanan bagi para pekerjanya dan penggunaan APD hendaknya menjadi kewajiban bagi pekerja, sehingga seluruh pekerja dapat terhindar dari akibat fatal kecelakaan bekerja.

Kata Kunci : Ergonomi, K3, ketersediaan APD

\section{PENDAHULUAN}

Perkembangan teknologi saat ini begitu pesat, sehingga peralatan sudah menjadi kebutuhan pokok pada lapangan pekerjaan. Artinya peralatan dan teknologi merupakan salah satu penunjang yang penting dalam upaya meningkatkan produktivitas untuk berbagai jenis pekerjaan. Disamping itu, akan terjadi dampak negatifnya bila kita kurang waspada menghadapi bahaya potensial yang mungkin akan timbul. Hal ini tentunya dapat dicegah dengan adanya antisipasi berbagai risiko. Antara lain kemungkinan terjadinya penyakit akibat kerja, penyakit yang berhubungan dengan pekerjaan dan kecelakaan akibat kerja.

Karena itu dalam rangka menjalankan usaha yang aman (safe business) maka program perlindungan bagi karyawan melalui penerapan Sistem Manajemen Kesehatan dan Keselamatan Kerja harus dilakukan secara konsisten. Hal ini sesuai Undang - undang No 36 Kesehatan dan No 44 Rumah Sakit Tahun 2009 pasal 164 tentang upaya kesehatan kerja diajukan untuk melindungi pekerja agar hidup sehat dan terbebas dari gangguan kesehatan serta pengaruh buruk yang diakibatkan oleh pekerjaannya (Atin 2012). Di indonesia kondisi keselamatan dan kesehatan di perusahaan masih terbilang rendah.

Menurut data statistik kecelakaan kerja PT. Jamsostek, kasus kecelakaan kerja pada tahun 2006 tercatat sebanyak 95.624 kasus, pada tahun 2007 ada 
83.714 kasus. Sedangkan pada tahun 2009 terdapat 96.324 kasus, pada tahun 2010 menjadi 98.711 kasus dan tahun 2011 sejumlah 99.491 kasus kecelakaan kerja. Secara umum, kejadian kecelakaan disebabkan dua hal yaitu, unsafe action dan unsafe conditioan. Tetapi $80 \%$ kasus kecelakaan di Indonesia disebabkan oleh unsafe action. Kasus kecelakaan kerja masih terjadi, dan mengakibatkan korban jiwa, di Makassar sesuai dengan data Ketenaga kerjaan, Pada tahun 2015 kasus kecelakaan kerja, dengan jumlah 110.286 kasus yang terjadi di 16.082 perusahaan, korban meninggal dunia hanya 530 orang. Dan pada tahun 2016 dari 101.367 kasus yang terjadi di 17.069 perusahaan, korban meninggal dunia sebanyak 2.382 orang. (Tribun, 2017).

\section{METODE}

PT. Makassar Beton Perkasa masih kurang akan penerapan ergonomi dan kesehatan dan keselamatan kerja, sehingga beberapa pekerja masih merasa tidak nyaman dalam bekerja.Penerapan ergonomi harus dilakukan agar pekerja merasa nyaman dan produktivitas semakin meningkat.

PT. Makassar Beton Perkasa masih kurang akan penerapan ergonomi dan kesehatan dan keselamatan kerja, sehingga beberapa pekerja masih merasa tidak nyaman dalam bekerja.Penerapan ergonomi harus dilakukan agar pekerja merasa nyaman dan produktivitas semakin meningkat.

Pengumpulan Data

Dalam penelitian ini dikumpulkan data dengan cara yaitu :

a) Data primer

Data Primer data yang diperoleh langsung di lapangan melalui wawancara dan observasi langsung ke responden dengan menggunakan daftar pertanyaan (kuesioner).

b) Data sekunder

Data sekunder adalah data yang diperoleh dari buku, artikel, jurnal, website, dan yang dianggap relevan dengan penelitian ini.

\section{Pengolahan dan analisis data}

Pengolahan data yang dilakukan dalam penelitian ini adalah dengan cara komputerisasi.

Penyajian data pada hasil yang digunakan adalah berbentuk tabel yang kemudian di narasikan sesuai dengan hasil yang telah ditetapkan.
HASIL

1) Sikap Posisi Kerja

Tabel 1

Distribusi Pekerja Menurut Sikap

Posisi Kerja Pada Bagian Kantor di Industri PT. Makassar Beton

Perkasa Tahun 2017

\begin{tabular}{cccc}
\hline No. & $\begin{array}{c}\text { Posisi Sikap } \\
\text { Kerja }\end{array}$ & Jumlah & Persentase \\
\hline $\mathbf{1}$ & Ergonomi & 10 & 25 \\
$\mathbf{2}$ & Tidak Ergonom & 30 & 75 \\
& Jumlah & 40 & 100 \\
\hline
\end{tabular}

2) Keluhan Kerja

Tabel 2

Distribusi Pekerja Menurut Keluhan Kerja

Pada Bagian Pabrik di Industri Pt.

Makassar Beton Perkasa Tahun 2017

\begin{tabular}{|c|c|c|}
\hline Jenis Keluhan & Frekuensi & $\%$ \\
\hline Kelelahan & 30 & 75 \\
\hline $\begin{array}{l}\text { Gangguan } \\
\text { Penglihatan }\end{array}$ & - & - \\
\hline Pegel/nyeri otot & 7 & 17.5 \\
\hline Pusing & - & - \\
\hline $\begin{array}{l}\text { Berkeringat dengan } \\
\text { banyak }\end{array}$ & 26 & 65 \\
\hline Dehidrasi (Haus) & 23 & 57.5 \\
\hline Kulit terasa panas & - & - \\
\hline $\begin{array}{l}\text { Kulit lembab (biang } \\
\text { keringat) }\end{array}$ & - & - \\
\hline $\begin{array}{l}\text { Konsentrasi kerja } \\
\text { menurun }\end{array}$ & 13 & 32 \\
\hline Badan terasa lemas & 14 & 35 \\
\hline Nyeri Punggung & 5 & 12.5 \\
\hline Kram Pada Kaki & 2 & 5 \\
\hline
\end{tabular}

3) Suhu

Tabel 3

Distribusi Hasil Pengukuran Suhu Ruangan Kerja Bagian Kantor di Industri PT. Makassar Beton Perkasa Tahun 2017

No $\quad$ Titik Suhu Satuan $\begin{gathered}\text { Luas } \\ \text { Ruangan }\end{gathered}$

\begin{tabular}{lllll}
\hline $\mathbf{1}$ & 1 & 21,8 & $\left({ }^{\circ} \mathrm{C}\right)$ & $18,7 \mathrm{~m} 2$ \\
$\mathbf{2}$ & 2 & 21,6 & $\left({ }^{\circ} \mathrm{C}\right)$ & $18,7 \mathrm{~m} 2$ \\
$\mathbf{3}$ & 3 & 21,5 & $\left({ }^{\circ} \mathrm{C}\right)$ & $18,7 \mathrm{~m} 2$ \\
$\mathbf{4}$ & 4 & 21,4 & $\left({ }^{\circ} \mathrm{C}\right)$ & $18,7 \mathrm{~m} 2$ \\
$\mathbf{5}$ & 5 & 21,8 & $\left({ }^{\circ} \mathrm{C}\right)$ & $18,7 \mathrm{~m} 2$ \\
\multicolumn{2}{c}{$\begin{array}{c}\text { Rata - } \\
\text { rata }\end{array}$} & $\begin{array}{l}21,6 \\
{ }^{\circ} \mathrm{C}\end{array}$ & & \\
\hline
\end{tabular}


4) Kelembaban

Tabel 4

Distribusi Hasil Pengukuran Kelembaban Ruangan Kerja Bagian Kantor di Industri PT. Makassar Beton Perkasa Tahun 2017

\begin{tabular}{ccccc}
\hline $\begin{array}{c}\mathbf{N} \\
\mathbf{0}\end{array}$ & $\begin{array}{c}\text { Titi } \\
\mathbf{k}\end{array}$ & $\begin{array}{c}\text { Kelembaba } \\
\mathbf{n}\end{array}$ & $\begin{array}{c}\text { Satua } \\
\mathbf{n}(\%)\end{array}$ & $\begin{array}{c}\text { Luas } \\
\text { Ruanga } \\
\mathbf{n}\end{array}$ \\
\hline $\mathbf{1}$ & 1 & 52,3 & $\%$ & $18,7 \mathrm{~m} 2$ \\
$\mathbf{2}$ & 2 & 52,1 & $\%$ & $18,7 \mathrm{~m} 2$ \\
$\mathbf{3}$ & 3 & 51,9 & $\%$ & $18,7 \mathrm{~m} 2$ \\
$\mathbf{4}$ & 4 & 52 & $\%$ & $18,7 \mathrm{~m} 2$ \\
$\mathbf{5}$ & 5 & 52,2 & $\%$ & $18,7 \mathrm{~m} 2$ \\
\multicolumn{2}{c}{$\begin{array}{c}\text { Rata - } \\
\text { rata }\end{array}$} & $52,10 \%$ & & \\
\hline
\end{tabular}

5) Alat Pelindung Diri

Tabel 5

Distribusi Hasil Pekerja yang

Menggunakan APD pada Bagian Pabrik di Industri PT. Makassar Beton Perkasa Tahun 2017

\begin{tabular}{|c|c|c|}
\hline \multirow[b]{2}{*}{$\begin{array}{c}\text { Ketersediaan } \\
\text { APD }\end{array}$} & \multicolumn{2}{|c|}{$\begin{array}{l}\text { Penggunaan } \\
\text { APD }\end{array}$} \\
\hline & $\begin{array}{l}\text { Mengg } \\
\text { unaka } \\
n\end{array}$ & $\begin{array}{l}\text { Tidak } \\
\text { Menggu } \\
\text { nakan }\end{array}$ \\
\hline Helm & 6 & 24 \\
\hline Masker & 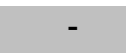 & 30 \\
\hline Sepatu Pelindung & 8 & 22 \\
\hline Sarung Tangan & 3 & 27 \\
\hline Pakaian Kerja & - & 30 \\
\hline $\begin{array}{l}\text { Pelindung Telinga } \\
\text { (ear plug) }\end{array}$ & & 30 \\
\hline
\end{tabular}

\section{PEMBAHASAN}

1) Gambaran penerapan sikap kerja ergonomis pada tenaga kerja

Bahwa seluruh responden pada bagian kantor telah bekerja dengan posisi ergonomis. Hal ini juga didukung dengan fasilitas yang telah disediakan oleh perusahaan sehingga memberikan kenyamanan dan keamanan pada saat bekerja. Faktor lain yang mendukung posisi kerja duduk yang ergonomis oleh pekerja adalah berdasarkan tingkat pengetahuan dan pemahaman pekerja yang sudah baik.Gambaran posisi kerja duduk ergonomis di kantor tersebut adalah posisi duduk tegak dengan punggung lurus dan bahu ke belakang. Paha menempel di dudukan kursi dan bokong menyentuh bagian belakang kursi.Berdasarkan hasil penelitian dari 40 responden pekerja PT. Makassar Beton Perkasa terdapat 10 responden $(25 \%)$ pekerja bagian kantor sudah sesuai dengan sikap kerja duduk yang ergonomi. Pada pekerja di bagian pabrik dalam posisi berdiri terdapat 30 responden $(75 \%)$ yang tidak sesuai dengan sikap kerja berdiri yang ergonomi.

\section{Gambaran keluhan Kerja}

Pada penelitian ini persentase keluhan terbesar terdapat pada pekerja di bagian pabrik dengan 30 responden (75\%) yang mengalami kelelahan, 26 responden $(65 \%)$ yang berkeringat dengan banyak, 23 responden (57.5\%) yang mengalami dehidrasi (haus), 14 responden (35\%) pekerja mengalami badan terasa lemas, 13 responden (32 $\%)$ pekerja mengalami konsentrasi kerja menurun, 7 responden (17.5\%) pekerja merasa pegal/nyeri otot, 5 responden $(12,5 \%)$ pekerja merasa nyeri punggung, 2 responden $(5 \%)$ pekerja merasa kram pada kaki. Dari hasil tersebut terlihat bahwa faktor kelelahan pada pekerja sangat besar. Kelelahan ini disebabkan oleh aktivitas pekerja menaiki dan menuruni tangga secara berulang ulang karena jika pekerja mengalami dehidrasi (haus) pekerja harus turun untuk mengambil minuman yang berada dibawah. Kondisi inilah juga yang mempengaruhi terjadinya keluhan lain

3) Kondisi suhu di lingkungan kerja bagian kantor PT. Makassar Beton Perkasa.

Berdasarkan hasil pengukuran suhu di dalam ruangan kantor PT. Makassar Beton Perkasa yang dilakukan sebanyak 5 titik dimana kondisi suhu rata-rata yaitu 21,60C. Temperatur tersebut merupakan kondisi yang masih memenuhi syarat untuk ruangan kerja sehingga pekerja akan merasa nyaman saat bekerja. Selain itu, ruangan kerja tersebut telah dilengkapi dengan Air Conditioner (AC). Selain dapat mengurangi keluhan kerja kondisi suhu yang optimum dapat meningkatkan kenyaman sehingga produktifitas dari tenaga kerja dapat meningkat. Sedangkan untuk suhu bagian pabrik tidak dilakukan pengukuran karena dapat di pastikan suhu pada bagian pabrik tidak memenuhi 
syarat, sebab pabrik tersebut berada di area terbuka. Faktor inilah yang menimbulkan keluhan pada tenaga kerja yaitu suhu lingkungan kerja.

4. Kondisi Kelembaban di lingkungan kerja bagian kantor PT. Makassar Beton Perkasa.

Kelembaban udara menggambarkan kandungan uap air di udara yang dapat dinyatakan sebagai kelembaban mutlak, kelembaban nisbi (relatif) maupun defisit tekanan uap air. Kelembaban mutlak adalah kandungan uap air (dapat dinyatakan dengan massa uap air atau tekanannya) per satuan volum. Kelembaban nisbi membandingkan antara kandungan/tekanan uap air aktual dengan keadaan jenuhnya atau pada kapasitas udara untuk menampung uap air. Kondisi kelembaban ruang kerja yang optimum pada umumnya berkisar antara $65-90 \%$. Kondisi kelembaban yang tidak optimum dapat menimbulkan keluhan pada pekerja.Berdasarkan hasil pengukuran kondisi kelembaban yang dilakukan di ruang kerja PT. Makassar Beton Perkasa dengan rata-rata kelembaban yang diukur dari 5 titik yaitu $51,2 \%$ Kelembaban tersebut merupakan masih dalam kategori yang kurang optimum.

5. Penggunaan Alat Pelindung Diri (APD) pada bagian pabrik di PT. Makassar Beton Perkasa.

Alat pelindung diri merupakan alat yang wajib digunakan sewaktu melakukan pekerjaan yang memungkinkan terjadinya kecelakaan kerja. Alat-alat pelindung diri harus sesuai dengan potensi bahaya dan resiko pekerjaannya sehingga efektif melindungi pekerja. Berdasarkan hasil pengamatan terhadap para pekerja bagian pabrik, diketahui bahwa seluruh responden pada bagian pabrik dari 30 pekerja. 6 pekerja diantaranya memakai helm pada saat bekerja, 8 pekerja memakai sepatu pelindung pada saat bekerja, 3 pekerja yang memakai sarung tangan pada saat bekerja. Kondisi ini sesuai dengan Peraturan Menteri Tenaga Kerja dan Transmigrasi Republik
Indonesia Nomor PER.08/MEN/VII/2010 tentang Alat Pelindung Diri. Kondisi ini juga, belum sepenuhnya sesuai dengan standar peraturan yang ditetapkan oleh pemerintah.

Oleh karena, pihak perusahaan tidak menyediakan alat pelindung diri bagi para pekerja, dengan alasan biaya yang terlalu mahal untuk menyediakan bagi semua pekerja. Hal inilah yang membuat sebagian pekerja tidak menggunakan alat pelindung diri. Namun, di sisi lain hal itu tidak mempengaruhi pekerja yang memiliki atau mempunyai alat pelindung diri. Masih ada pekerja juga yang masih sadar akan perlunya alat pelindung diri pada saat bekerja, meskipun kelengkapannya belum sesuai dengan standar.

\section{KESIMPULAN}

Penerapan kesehatan dan keselamatan kerja sering ditempatkan pada prioritas rendah dan terakhir dalam operasional perusahaan, hal ini disebabkan oleh beberapa faktor:

a. Tidak adanya petugas K3 dan ergonomi pada perusahaan

b. Manajemen masih memberikan prioritas rendah dan terakhir pada program K3 dan ergonomi

c. Modal dan pengetahuan mengenai K3 dan ergonomi yang masih kurang juga menjadi faktor penghambat. dalam program kerja perusahaannya.

\section{SARAN}

a. Bagi pekerja bagian produksi PT Makassar beton Perkasa Diharapkan meningkatkan sikap kerja yang positif dan ergonomis dalam bekerja dan selalu memanfaatkan jam istirahat dengan sebaik mungkin untuk menjaga kesehatan tubuh dan menaati prosedur kerja yang telah ditetapkan agar risiko keluhan dapat di minimalisir

b. Bagi PT. Makassar Beton Perkasa Perusahaan diharapkan menyediakan APD sesuai jumlah pekerja. Agar pekerja bagian pabrik dapat menggunakan APD, sehingga terhindar dari potensi bahaya di tempat kerja.

\section{DAFTAR PUSTAKA}

Arda, A. 2007. Waspada Nyeri pinggang mengakibatkan. (online) (http: // id. shvoong. Com / medicine-andhealth/1650679. Diakses tanggal 20 Februari 2017)

Arnita. 2006. Majalah Farmacia edisi januari 2006 (online) (http: // www. Majalah - farmacia. 
com diakses tanggal 17 februari 2017)

Atin. 2012. Masalah Ergonomi. (online) (http: // atin- kuliahku. blogspot. co. id diakses tanggal 11 Februari 2017)

Bayu. Purnomo. Pengertian Ergonomi (online) (http: // purnamabgp. blogspot. co. id/ 2012/12/ pengertian ergonomi. html diakses tanggal 10 Februari 2017)

Brown, A. and Mackeler, L.S. 1999. Diagnose of Mechanical LBP in a I aborerjornal Of Orthopaedic \& Sport Physical Therapy, Volume $29 \quad$ (9), American Physical Therapy Association. Crystal City. (http:// www.emedicine.com. di akses tanggal 20 Februari 2017)

Nurrahman. 2016. "Hubungan Masa Kerja Dan Sikap Kerja Terhadap Kejadian Low Back Pain Pada Penenun Di Kampoeng Bni Kab.Wajo". Program Studi Fisioterapi Fakultas Kedokteran Universitas Hasanuddin, Makassar (KTI tidak diterbitkan).

Parjoto, S. 2007. Pentingnya Memahami Sikap Tubuh Dalam Kehidupan. MajalahFisioterapi Indonesia Vol. 7 No. 11/Mei 2007.

Peraturan Menteri Tenaga Kerja dan Transmigrasi Republik Indonesia Nomor Per.08/MEN/VII/2010 tentang Alat Pelindung Diri. (Diakses pada tanggal 22 juli 2017).

Purnomo, Hari. 2013. Antropometri dan Aplikasinya. Yogyakarta: Graha IImu.

Rachma, Noer. 2002. Aspek Klinis Nyeri Punggung Bawah; Simposium Pelantikan Dokter Periode 142, Surakarta, 21 Desember.

Rahmat Febriandi. 2014. Pengaruh Ergonomi Dan Psikologi Terhadap Produktivitas Tenaga Kerja PT. Cipta Beton Perkasa Makassar. Diploma III Jurusan Kesehatan Lingkungan Politeknik Kesehatan Kemenkes Makassar. (KTI tidak diterbitkan)

Santoso, Gempur. 2010. Manajemen Perawatan Pabrik Dengan Pendekatan Ergonomis, Edisi Pertama. Prestasi Pustaka Publisher. Jakarta

Santoso, Gempur. 2013. Ergonomi Terapan. Jakarta; Prestasi Pustaka.

Sedarmayanti. 2001. Sumber Daya Manusia dan Produktivitas Kerja. Mandar Maju: Bandung.

Sobotta. 2000. Atlas Anatomi Manusia. Jakarta : Buku Kedokteran

Solusi Kesehatan. (online) (http: //segiempat. Com /sehat/ solusi kesehatan/kesehatan-gigi-dantulang/kelainan-bentuk-tulang-karena -duduk -terlalu - lama diakses tanggal 16 Februari 2017)

Tribunnews. 16 Februari 2017. Kasus Kecelakaan Kerja Di SulSel Meningkat, (online), (http: // makassar. tribunnews. Com diakses tanggal 24 Februari 2017)

Undang-Undang No.1 Tahun 1970 pasal 14 butir c Bahwa Pengurus (Pengusaha) Diwajibkan Mengadakan Secara Cuma-Cuma Semua Alat Pelindung Diri (APD) Yang Diwajibkan Pada Tenaga Kerja Di bawah Pimpinannya.

Wuri Cahyadi. 2012. Pengaruh Suhu Ruang Terhadap Keluhan Subyektif Gejala Heat Exhaustion Bagian Injeksi PT.Arisamandiri Pratama Demak Under Graduates thesis, Universitas Negeri Semarang 